Table 1. ANALYSES OF POLYSaccharides (PERCENTAGE)

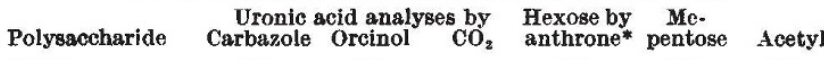

$\begin{array}{lllllll}K-235 & 14 & 23 & & 80 & 21 & 6 \cdot 8 \\ K-1.2 W & 16 & 25 & & 83 & 21 & 6 \cdot 8 \\ M-6 \text { of } K \text {-12 } & 17 & 27 & & 83 & 23 & 6 \cdot 8 \\ \text { Mucoid } \boldsymbol{E} \text {. coli } & 17 & 22 & 20 & 83 & 20 & 8.0\end{array}$

* Anthrone values are reported using galactose as standard; they are uncorrected, and therefore include the fucose. Because glucose, which is als present, gives a somewhat more intense colour than galactose, the tota approximately 55 per cent.

These data show that the polysaccharide isolated from the mucoid $E$. coli is identical to the capsular materials alaborated by $E$. coli strains $K-12, K-235$ and the $M-6$ mutant of $K-12$ which have been previously described ${ }^{11-13}$ and seem to be identical to each other. This identity has also been suggested for several additional polysaccharides of other Enterobacteriaceae ${ }^{14}$. The structure of the $M-6$ mutant of $K-12$ has been partially determined ${ }^{13}$. The polysaccharide isolated from the organism obtained from this patient with cystic fibrosis is therefore not related to the alginate-like polymer produced by the Pseudomonads.

It is of considerable interest that all the polysaccharides described in this paper seem to contain o-acetyl groups as shown by infrared and analytical data (the analytical method used ${ }^{10}$ involves distillation of acetic acid, and is therefore fairly specific). It is also of interest in this connexion that the infrared spectra published originally $^{12,15}$ for these polymers indicated the presence of $o$-acetyl, but this was not referred to by the authors.

We thank Dr J. P. Kilbourn, University of Oregon Medical School, for the cultures of the organisms.

ALFRED LiNKer

Leigh R. Evans

Departments of Biological Chemistry and Pathology,

University of Utah College of Medicine, and the

Veterans Administration Hospital,

Salt Lake City, Utah.

Received March 4; revised April 1, 1968.

' Jinker, A., and Jones, R. S., Nature, 204, 187 (1964).

'Linker, A., and Jones, R. S., J. Biol. Chem., 241, 3845 (1966).

Carlson, D. M., and Matthews, L. W., Biochemistry, 5, 2817 (1966).

4 Kilbourn, J. P., Grach, J. L., and Campbell, R. A., J. Pediat. (in the press, 1968).

${ }^{5}$ Seifter, S., Dayton, S., Novic, B., and Muntwyler, E., Arch. Biochem. Biophys., 25, 191 (1950)

'Dische, Z., J. Biol. Chem., 167, 189 (1947).

'Brown, A. H., Arch. Biochem. Biophys., 11, 269 (1946).

Tracey, M. V., Biochem. J., 43, 185 (1948).

Dische, Z., and Shettles, L. B., J. Biol. Chem., 175, 595 (1948).

10 Ludowieg, J., and Dorfman, A., Biochim. Biophys. Acta, 38, 212 (1960).

"Goebel, W. F., Proc. US Nat. Acad. Sci., 49, 464 (1963).

${ }^{12}$ Sapelli, R., and Goebel, W. F., Proc. US Nat. Acad. Sci., 52, 265 (1964).

${ }^{13}$ Rodén, L., and Markovitz, A., Biochim. Biophys. Acta, 127, 252 (1966).

it Anderson, E. S., and Rogers, A. H., Nature, 198, 714 (1963).

'J Jaffe, H., Proc. US Nat. Acad. Sci., 49, 464 (1963).

\section{Cellular Uncoupling in Cancerous Thyroid Epithelium}

EARLIER work at this laboratory has shown that cancerous liver cells, unlike normal ones, are not in ionic communication with each other ${ }^{1,2}$. This study has now been extended to another set of epithelial tissues.

Normal thyroids (rat, hamster) and transplanted thyroid cancers (Fischer rat tumour types $1-C 2,1-1 D$, $1-8,1-4,1-5 A, 1-5 E, 1-6,1-7,16-1,16-4,1-3$ (ref. 3); and Syrian golden hamster tumour type Thy-2 of J. G. Fortner), were isolated in $\mathrm{Krebs}$ solution $\left(23^{\circ}-25^{\circ} \mathrm{C}\right)$ and intercellular communication was measured within 10-45 min. The technique of measurement, described in detail elsewhere ${ }^{1}$, consisted essentially of passing a current $\left(10^{-8} \mathrm{~A}\right)$, by means of a micro-electrode, between the inside and the outside of a cell, and recording the resulting changes in membrane potential with micro- electrodes positioned inside this cell $\left(V_{I}\right)$, in an adjacent cell $\left(V_{I I}\right)$, and in more distant cells.

In normal thyroid tissue, such intracellular potential changes are detectable over several cell junctions from the electrode which is passing the current; the communication ratio, $V_{I I} / V_{I}$, is about $0 \cdot 25$. The principal route of the current is clearly from the interior of one cell to that of another cell. Corresponding voltages are much smaller outside cells than inside them, and are of the same order of magnitude as in the bathing solution. Thus normal thyroid cells, within any given follicle, communicate well.

Cancer thyroid cells, on the other hand, do not com. municate to any detectable degree. The various cancer types examined differ widely in growth rate and differen. tiation. For example, cells of rat tumour type 1-1C2 grow slowly and resemble normal thyroid cells relatively closely in follicular arrangement and the ability to make thyroglobulin and thyroxine. At the other extreme are the fast growing and widely deviant cells of types 16-1 and 1-3 which are not arranged in follicles and do not make thyroglobulin or thyroxine ${ }^{3}$. But, regardless of their rate of growth and extent of functional deviation, all the cancer types examined lack detectable cellular communica. tion: the communication ratios are less than 0.002 , the limit of resolution of the method; and the resistances between cell interior and exterior (cell input resistances) are higher than in normal thyroid cells (Table 1). Furthermore, the membrane potentials at zero current are sig. nificantly lower than in normal cells.

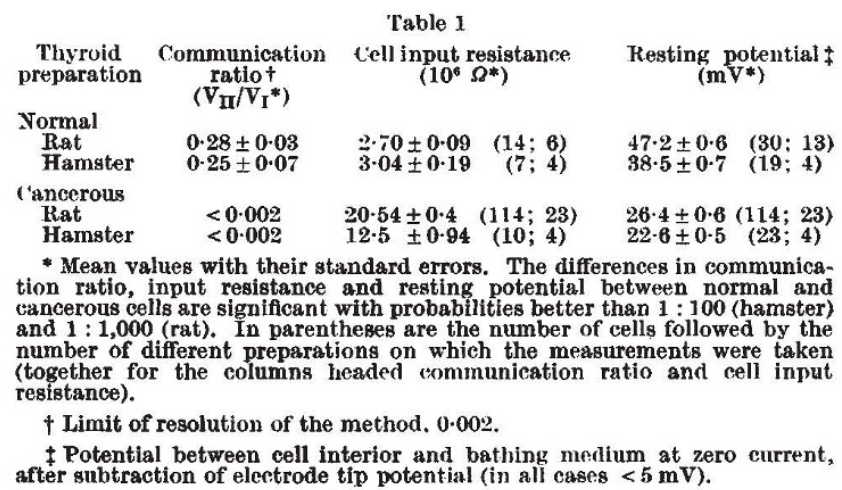

We thank Drs S. Wollman, G. Sichuk and J. G. Fortner for tumour-carrying animals. This work was supported by grants from the US National Institutes of Health and US National Science Foundation.

\section{A. Jamakosmanović}

W. R. LOEWENSTEIN

Cell Physics Laboratory,

Physiology Department.

Columbia University College of Physicians and Surgeons, New York.

Received April 5, 1968

${ }^{1}$ Loewenstein, W. R., and Kanno, Y., J. Cell Biol., 38, 225 (1967).

${ }^{2}$ Loewenstein, W. R., Ann. VY Acad. Sci., 187, 441 (1966).

Wollman, S. H., Rec. Prog. Hormone Res., 19, 579 (1963).

\section{Cellular Uncoupling in Cancerous Stomach Epithelium}

Measurements of cellular communication, similar to those described by Jamakosmanović and Loewenstein in the preceding report, were performed on the surface epithelium of normal and cancerous human stomach. Pieces of stomach from surgical patients were isolated into Krebs solution, and electrical measurements were made on the surface epithelium away from the cut edges, $1.5 \mathrm{~h}$ after the blood supply had heen interrupted. 